\title{
Factors relating to the development of respiratory symptoms in coffee process workers
}

\author{
K E Thomas, C J Trigg, P J Baxter, M Topping, J Lacey, B Crook, P Whitehead, J B Bennett, \\ R J Davies
}

\begin{abstract}
After several cases of occupational asthma had been reported in a coffee processing factory in England, 197 coffee workers representing $80 \%$ of the production workforce were studied to determine the factors affecting the development of work related respiratory symptoms of wheeze, cough, and dyspnoea. Two computer administered questionnaires concerning the presence of respiratory symptoms and the occurrence of work related respiratory symptoms were used. Workers underwent skin prick testing to green coffee bean extract (GCB) and 11 common inhalant allergen extracts and bronchial provocation testing with methacholine. The presence of specific immunoglobulin E (IgE) antibodies to GCB and castor bean extract (CAB) were determined by a radioallergosorbent test (RAST). The prevalence of work related respiratory symptoms was $12 \cdot 7 \%$, bronchial hyperresponsiveness $30 \%$, atopy $54 \%$, positive GCB skin prick test $14.7 \%$, positive GCB RAST $14 \%$, and positive CAB RAST $14 \cdot 7 \%$. None of the workers was sensitised to fungi present in the factory and the numbers of certain species of fungi, despite being greater than may be found out of doors or in an uncontaminated indoor environment, were fewer than are generally associated with the presence of work related respiratory symptoms among agricultural workers. Storage mites were not isolated. Green coffee bean extract and CAB RAST were
\end{abstract}

Academic Department of Respiratory Medicine, St Bartholomew's Hospital, London EC1A 7BE

K E Thomas, C J Trigg, P Whitehead, J B Bennett, R J Davies

Health and Safety Executive, Barking, Essex IG11 8HF

P J Baxter

Health and Safety Executive, Edgware Road, London NW2 6LN

M Topping

AFRC Institute of Arable Crops Research, Rothamsted Experimental Station, Harpenden, Herts J Lacey, B Crook significantly correlated using the McNemar test but there was limited allergenic cross reactivity in RAST inhibition studies of the two extracts. The only factors that were significantly and independently associated with work related symptoms were CAB RAST and duration of employment. Bronchial hyperresponsiveness was not independently associated with work related respiratory symptoms. The significant independent associations of bronchial hyperresponsiveness included GCB RAST, duration of employment, and resting forced expiratory volume in one second. Exposure to CAB, a highly potent antigen, may be overriding the effects of other factors such as GCB, atopy, bronchial hyperresponsiveness, and smoking. This study suggests that $\mathrm{CAB}$ contamination remains a potential problem in the coffee processing industry and all efforts to eliminate it from the working environment should continue.

Figley et al were the first to describe occupationally related symptoms in coffee process workers. ${ }^{1}$ They concluded that the potent castor bean (CAB) antigen contaminating burlap bags used to ship green coffee beans (GCB) was responsible for a large proportion of the work related respiratory symptoms in the coffee industry. Several reports since have shown that exposure to coffee bean dust can also cause work related respiratory symptoms.

Zuskin $e t a l^{2}$ compared respiratory symptoms and lung function in two groups of coffee workers employed in the processing of either roasted coffee or green coffee, with those in a control group matched for age, height, and smoking habits. In women, chronic respiratory symptoms were significantly more prevalent in the coffee workers than in the controls whereas in men, dyspnoea and nasal catarrh were significantly more frequent than in controls. The greatest difference, however, was seen in measurement of maximum expiratory flow rates at $50 \%$ vital capacity $\left(\mathrm{MEF}_{50}\right)$. During the Monday workshift significant decreases in $\mathrm{MEF}_{50}$ occurred in both roasters and green coffee workers. Changes in 
forced expiratory volume in one second $\left(\mathrm{FEV}_{1}\right)$ and forced vital capacity (FVC) were less obvious, and Zuskin $e t \mathrm{al}^{2}$ suggested that coffee bean dust mostly affected the small airways.

Karr et $a l^{3}$ studied eight coffee workers and eight controls. Six workers had work related respiratory symptoms of asthma, rhinitis, conjunctivitis, urticaria and pruritus, and positive skin tests to GCB and factory dust antigens. The asymptomatic workers and eight controls were skin test negative. Also, sera from the six symptomatic workers had antibodies specific to GCB and CAB as indicated by radioallergosorbent tests (RAST) and the factory dust contained both GCB and CAB antigens. Radioallergosorbent test inhibition showed no cross reactivity between GCB and CAB.

Osterman $\mathrm{et} \mathrm{al}^{4}$ showed a high prevalence of work related respiratory symptoms $(40 \%)$ and skin test positivity to $\mathrm{GCB}$ and $\mathrm{CAB}(22 \%)$ in a cross sectional study of 129 workers. They noted that positive GCB RAST only occurred with a positive CAB RAST, suggesting an interrelation between sensitisation to the two agents. The same group 5 made a limited survey of bronchial responsiveness in 22 symptomatic coffee workers of whom 14 had bronchial hyperresponsiveness but the prevalence of bronchial hyperresponsiveness and its relation with work related respiratory symptoms, coffee, and CAB sensitisation in a workforce have not been studied. Bronchial hyperresponsiveness after challenge with allergen $^{6}$ and exposure to occupational agents such as western red cedar ${ }^{7}$ is well documented and the association between bronchial hyperresponsiveness, respiratory symptoms, and greater requirements for medication is well recognised. ${ }^{8}$

The purpose of this study was to investigate the roles of airway hyperresponsiveness and antigens from airborne fungi, GCB, and CAB in the development of respiratory symptoms in the workforce of a coffee processing factory.

\section{Materials and methods \\ PROCESSING OF RAW GCB}

Raw green coffee beans from Africa, South East Asia, and Central and South America are delivered to the warehouse of the plant by ventilated container lorries. The beans are carried in burlap sacks. It is not known whether these sacks have previously been used for other products.

The coffee factory (fig 1 ) is divided into three main areas; the green bean warehouse, the roasting area, and processing areas. When the beans are required the bags are split open and emptied through ground level grids with underfloor dust extraction into automated cleaning equipment from which they are blown along pipes to silos in the roasting plant. The beans are weighed and blended before roasting and then transferred to the third area for further processing.

\section{THE SUBJECTS}

All production workers with potential exposure to coffee bean dust and 47 unexposed production workers were invited to take part in the study. All but one were men. The unexposed workers can be considered

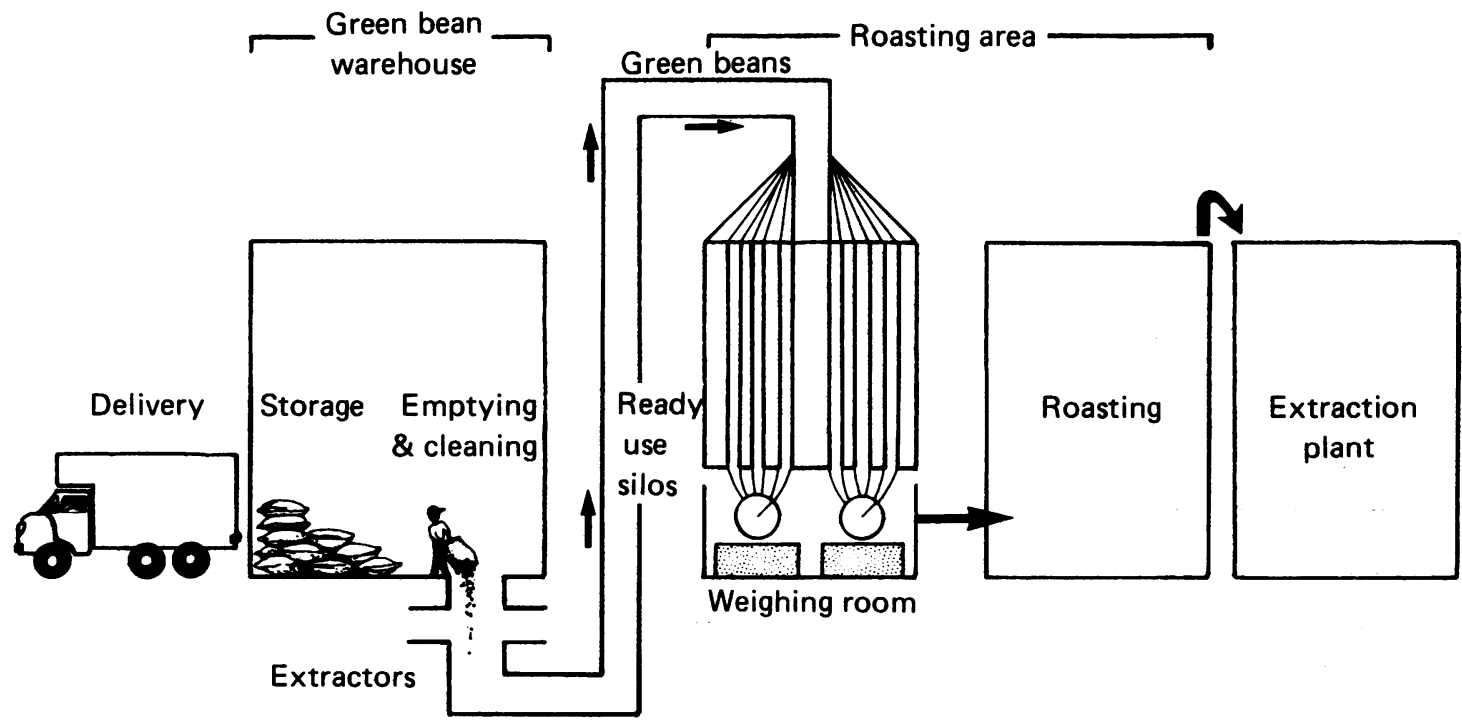

Figure 1 Schematic representation of the coffee processing factory. 
a control group as their place of work is separated from the main factory. Each of the 197 workers who responded, representing $80 \%$ of the workforce, was seen in the works medical centre on one occasion over a two week period in November 1985 when all tests were performed.

\section{COMPUTER ADMINISTERED QUESTIONNAIRES}

Each subject answered two computer administered questionnaires. The first was based on the MRC questionnaire 9 and concerned the presence of respiratory symptoms. ${ }^{10}$ The second inquired after their work related respiratory symptoms. ${ }^{11} \mathrm{~A}$ subject was defined as having work related respiratory symptoms if symptoms of wheeze, cough, or dyspnoea were brought on by contact with coffee beans at work and improved when away from work for weekends or on holidays.

\section{SPIROMETRY}

Forced expiratory volume in one second $\left(\mathrm{FEV}_{1}\right)$ and forced vital capacity (FVC) were measured on one occasion during the workshift using a Vitalograph dry bellows spirometer (Vitalograph, Buckingham, England). The best of two reproducible attempts measured at body temperature and pressure standard was recorded.

\section{BRONCHIAL RESPONSIVENESS TO METHACHOLINE}

Bronchial responsiveness to methacholine was determined by provocation testing using a range of concentrations of methacholine (doubling from 0.5 $\mathrm{mg} \mathrm{ml}^{-1}$ to $32 \mathrm{mg} \mathrm{ml}^{-1}$ ) by the method of Bennett and Davies. ${ }^{12}$ Briefly, $5 \mathrm{ml}$ of solution were placed in a DeVilbiss 646 nebuliser driven at a flow rate of 61 $\mathrm{min}^{-1}$. Each subject (with the nose clipped) inhaled the aerosol for two minutes during tidal breathing through a mouthpiece. The procedure was terminated if $\mathrm{FEV}_{1}$ fell by $15 \%$ or more after inhalation of the control solution. Otherwise, doubling concentra-

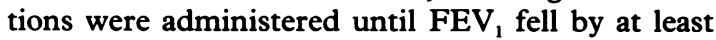
$20 \%$ from the post-control value or the maximum concentration was reached. The concentration provoking a $20 \%$ fall in the $\mathrm{FEV}_{1}\left(\mathrm{PC}_{20} \mathrm{FEV}_{1}\right)$ was then calculated by linear interpolation from the last two points on the logarithmic dose response curve. In a previous study the range of $\mathrm{PC}_{20} \mathrm{FEV}_{1}$ found in symptomatic asthmatic subjects was $2 \mathrm{mg} \mathrm{m}^{-1}$ (equivalent to $11 \mu \mathrm{mol}$ cumulative dose) or less and we used this value as an arbitrary cut off point to indicate bronchial hyperresponsiveness. ${ }^{12}$

\section{TOTAL DUST}

Total dust and respirable dust were measured as described previously. ${ }^{13}$ Personal samplers were worn by volunteer workers while carrying out their normal duties. Samplers were worn by four workers in the roasting area throughout an afternoon shift, by two workers employed to tip beans into the cleaner, and by seven workers while unloading sacks of coffee beans from a container lorry.

\section{MICROBIOLOGICAL AIR SAMPLING}

Andersen six stage impactors ${ }^{14}$ were used to recover viable micro-organisms from air. The impactors were held $1.5 \mathrm{~m}$ above the floor and operated at a flow rate of $251 \mathrm{~min}^{-1}$ for 0.5-1.0 minute for each set of agar plates. Different groups of micro-organisms were isolated by using the following media and incubation temperatures.

\section{Total bacteria}

Tryptone Soya agar incubated at $25^{\circ} \mathrm{C}$ for up to five days.

\section{Total fungi}

Two per cent malt extract agar and dichloran rose bengal chloramphenicol agar, ${ }^{15}$ the last used to restrict fast growing Mucoraceae, incubated at $25^{\circ} \mathrm{C}$ for up to seven days.

\section{Xerotolerant fungi}

Dichloran glycerol agar ${ }^{16}$ or malt salt agar to isolate fungi capable of growing in conditions of low water availability; incubated at $25^{\circ} \mathrm{C}$ for up to 10 days.

Concentrations of airborne micro-organisms were calculated from the number of colonies on plates from the six stages of the Andersen sampler, with colony counts on stages 3 to 6 adjusted for multiple deposition beneath jets ${ }^{14}$ and expressed as colony forming units (cfu) $\mathrm{m}^{-3}$ air sampled. Representative isolates were identified by colony and microscopical morphology. Duplicate samples for airborne microorganisms were collected on three occasions from the roasting area, the green bean tipping area, and the area of sack unloading from the container lorry.

\section{ENTOMOLOGICAL ANALYSIS OF COFFEE DUST}

Samples of dust taken from the exhaust ventilation system in the factory were examined under a low power microscope for the presence of insects, especially storage mites or their remains.

\section{PREPARATION OF FUNGAL EXTRACTS}

Freeze dried extracts were prepared from Alternaria spp culture filtrate and mycelia of Cladosporium spp, Aspergillus niger, $A$ flavus, $A$ ochraceus, and $A$ fumigatus. Each was reconstituted in $4 \mathrm{ml}$ of phosphate buffered saline (PBS) and centrifuged at $1000 \mathrm{~g}$. The reconstituted extracts were stored at $-20^{\circ} \mathrm{C}$.

\section{PREPARATION OF GCB AND CAB EXTRACTS}

Green coffee bean and CABs were each ground in a blender and $20 \% \mathrm{w} / \mathrm{v}$ extracts were prepared by mixing ground beans with PBS overnight at $4^{\circ} \mathrm{C}$. 
Insoluble material was removed by centrifugation at $48000 \mathrm{~g}$ for 30 minutes at $4^{\circ} \mathrm{C}$ and the supernatant dialysed against $\mathrm{PBS}$ at $4^{\circ} \mathrm{C}$. The CAB extract was clarified by passage through a $0.8 \mu \mathrm{m}$ Millex filter (Millipore Ltd) and both extracts were stored at $-20^{\circ} \mathrm{C}$.

PREPARATION OF SKIN PRICK TEST MATERIAL

Coffee bean extract $(10 \mathrm{ml})$ was dialysed overnight at $4^{\circ} \mathrm{C}$ against Coca's solution $(0.03 \mathrm{M}$ sodium bicarbonate, $0.086 \mathrm{M}$ sodium chloride, and $0.4 \%$ phenol). Dialysed material $(2.5 \mathrm{ml})$ was passed through a Millex filter fitted with a $0.22 \mu \mathrm{m}$ membrane (Millipore Ltd) into a sterile vial containing $2.5 \mathrm{ml}$ glycerol and $0 \cdot 25 \mathrm{ml} 4 \%$ phenol.

\section{SKIN PRICK TESTING}

Skin prick testing was performed on the volar surface of the forearm using the following common inhalant allergens and occupational allergens: house dust $150 \% \mathrm{w} / \mathrm{v}$, Dermatophagoides pteronyssinus $1.2 \% \mathrm{w} /$ $\mathrm{v}$, grass pollen $2 \cdot 5 \% \mathrm{w} / \mathrm{v}$, cat fur $150 \% \mathrm{w} / \mathrm{v}$, dog hair $150 \%$ w/v, Aspergillus fumigatus $5 \%$ w/v, Aspergillus niger, Cladosporium spp, Penicillium spp, Candida albicans $10 \% \mathrm{w} / \mathrm{v}$, mixed yeasts $10 \% \mathrm{w} / \mathrm{v}$ (all supplied by Bencard, UK). An extract of mixed GCB was used at $1 \%$ and $10 \% \mathrm{w} / \mathrm{v}$.

A positive skin prick test was defined as a weal at least $1 \mathrm{~mm}$ greater in diameter than the negative control. Subjects with at least one positive skin test to the range of allergens used, with the exclusion of GCB extract, were considered atopic for the purpose of the study.

\section{RADIOALLERGOSORBENT TEST (RAST)}

Venous blood $(10 \mathrm{ml})$ was obtained from each patient to measure specific IgE to GCB and CAB.

\section{MEASUREMENT OF SPECIFIC IgE}

Extracts were coupled to paper discs (Schleicher and Schull No 589/3) activated with cyanogen bromide, using the following amounts of allergen extract per $100 \mathrm{mg}$ of activated discs; GCB extract $2.5 \mathrm{ml}$ and CAB extract $0.375 \mathrm{ml}$.

Serum $(200 \mu \mathrm{l}$ of a 1:4 dilution in PBS) was incubated overnight at room temperature with an allergen disc. Discs were washed three times with $1.5 \mathrm{ml}$ of $0.9 \%$ saline containing washing solution additive (Pharmacia, Uppsala, Sweden). Fifty microlitres of ${ }^{125}$ I labelled rabbit antihuman IgE (Pharmacia) and $50 \mu$ lof PBS were then added. After further overnight incubation at room temperature, the discs were again washed three times with the washing solution and bound ${ }^{125} \mathrm{I}$ was measured in counts per minute (cpm) using a $\gamma$-counter. All the sera were tested in duplicate. The results are expressed as RAST \% binding defined as the percentage of added cpm bound to the allergen disc.

\section{RAST INHIBITION}

Aliquots of a pool of sera with high IgE concentration to either CAB or GCB extract were mixed with increasing amounts of soluble phase allergen, then a solid phase allergen disc was added and the IgE bound to the disc measured as described above. The results were expressed as the percentage inhibition resulting from the addition of the soluble phase allergen.

\section{STATISTICAL METHODS}

Analysis of the associations of work related symptoms and bronchial hyperresponsiveness was done using data collected from the 150 exposed workers. Fisher's exact test or $\chi^{2}$ testing was followed by stepwise binary logistic regression analysis (BMDP statistical software Inc, Los Angeles, USA). Reference ranges for CAB and GCB RAST were obtained from the unexposed control group.

Initially prevalence of symptoms among the 150 workers was tabulated. The $\chi^{2}$ test was then used to determine a significant association between any two variables. If any of the expected frequencies in the $\chi^{2}$ contingency table were less than five then the Fisher's exact test was used. ${ }^{17}$ Binary logistic regression analysis was carried out to estimate the magnitude of the effect of one variable after allowance for the effects of other variables. The McNemar test was used to assess agreement between the two sets of RAST results. ${ }^{18}$

\section{Results}

SURVEY RESPONSE

Of the $\mathbf{2 4 6}$ workers invited to take part in the study $197(80 \%)$ accepted, forming the study population. Bronchial provocation testing was not performed on 13 subjects, seven of whom had an FEV of more than two standard deviations (SD) below their predicted value, two of whom had ischaemic heart disease, and four who refused the test. Blood samples were obtained from 172 of 197 workers.

\section{SUBJECT CHARACTERISTICS}

All but one of the subjects were men, reflecting the predominance of men in the workforce. Workers

\section{Table 1 Characteristics of study population of 197 coffee} workers

\begin{tabular}{|c|c|c|c|c|}
\hline$J o b$ & $\begin{array}{l}\text { No in } \\
\text { survey } \\
(\text { No }(\%))\end{array}$ & $\begin{array}{l}\text { Age } \\
\text { range } \\
(y)\end{array}$ & $\begin{array}{l}\text { Smoking } \\
(\text { No }(\%))\end{array}$ & $\begin{array}{l}\text { Atopy } \\
(\text { No }(\%))\end{array}$ \\
\hline \multirow{3}{*}{$\begin{array}{l}\text { GCB warehouse } \\
\text { Roasting area } \\
\text { Extraction area } \\
\text { (control group) } \\
\text { All areas } \\
\text { (maintenance } \\
\text { workers) }\end{array}$} & $\begin{array}{l}29(14 \cdot 7) \\
83(42 \cdot 1)\end{array}$ & $\begin{array}{l}20-63 \\
18-64\end{array}$ & $\begin{array}{l}19(65 \cdot 5) \\
30(36 \cdot 1)\end{array}$ & $\begin{array}{l}17(58 \cdot 6) \\
43(51 \cdot 8)\end{array}$ \\
\hline & $47(23 \cdot 8)$ & $23-61$ & $26(55 \cdot 3)$ & $23(48 \cdot 9)$ \\
\hline & $38(19 \cdot 2)$ & $17-62$ & $17(44 \cdot 7)$ & $19(50 \cdot 0)$ \\
\hline
\end{tabular}


Table 2 Mean concentrations of airborne dust and microorganisms in three work areas

\begin{tabular}{llll}
\hline Analysis & $\begin{array}{c}\text { Container } \\
\text { unloading }\end{array}$ & Tipping & Roasting \\
\hline Total dust $\left(\mathrm{mg} \mathrm{m}^{-3}\right)$ & $3 \cdot 2$ & $3 \cdot 2$ & $1 \cdot 3$ \\
Respirable dust $\left(\mathrm{mg} \mathrm{m}^{-3}\right)$ & $0 \cdot 25$ & $0 \cdot 22$ & $0 \cdot 15$ \\
Bacteria, $25^{\circ} \mathrm{C}^{\star}$ & $4 \cdot 12$ & $8 \cdot 50$ & 1.90 \\
Bacteria, $55^{\circ} \mathrm{C}^{\star}$ & $2 \cdot 64$ & 1.00 & 1.42 \\
Fungi, $25^{\circ} \mathrm{C}^{\star}$ & $8 \cdot 14$ & 3.40 & $5 \cdot 65$ \\
Xerophilic fungi, $25^{\circ} \mathrm{C}^{\star}$ & 16.24 & $2 \cdot 79$ & 3.72 \\
\hline
\end{tabular}

*Colony forming units $\mathrm{m}^{-3} \times 10^{-3}$.

were divided into four groups according to their job site. One group comprised workers from the GCB warehouse, one from the roasting plant, one from the extraction area, and the fourth group consisted of people who worked throughout the factory. Workers from the extraction area represented the control group as they were only exposed to coffee beans after the roasting process, which destroys the antigenic activity of the beans. ${ }^{19}$ Table 1 shows the characteristics of the study population.

\section{AIRBORNE DUST}

Table 2 shows the average total and respirable dust concentrations measured in the GCB warehouse and the roasting area. The GCB warehouse was the most dusty area in the factory with concentrations up to 3.2 $\mathrm{mg} \mathrm{m}^{-3}$ whereas concentrations in the roasting area were only $1.3 \mathrm{mg} \mathrm{m}^{-3}$.

\section{AIRBORNE MICRO-ORGANISMS}

Total airborne bacteria were between $10^{3}$ and $10^{4} \mathrm{cfu}$ $\mathrm{m}^{-3}$ and were mostly common dust borne Gram positive Bacillus spp or Micrococcus spp. Thermophilic actinomycetes and thermophilic bacteria, mostly Bacillus spp, were isolated only infrequently. Total airborne fungi also averaged between $10^{3}$ and $10^{4} \mathrm{cfu} \mathrm{\textrm {m } ^ { - 3 }}$ with numbers being greatest during container unloading. Similarly mean concentrations of xerotolerant fungi were much greater during container unloading than in any other area (table 2), showing the influence of contaminants in the coffee dust on the workplace air.

Cladosporium and Penicillium spp were isolated from almost all samples and yeasts from $75 \%$. In areas where unprocessed beans were handled, the most prevalent fungal species were the xerophilic species Wallemia sebi and Eurotium spp, and four Aspergillus spp, $A$ niger, $A$ tamarii, $A$ ochraceus, and the $A$ glaucus group.

\section{ENTOMOLOGICAL ANALYSIS OF COFFEE DUST}

Examination of collected dust showed little evidence of insect infestation. Remains of bark beetles (Scolytidae) were found in some samples but storage mites or their remains were absent from all samples examined.

\section{PREVALENCE OF POSITIVE TESTS}

Table 3 presents a summary of the prevalence of work related respiratory symptoms and positive tests among the exposed workforce.

\section{WORK RELATED RESPIRATORY SYMPTOMS}

Work related respiratory symptoms of wheeze, cough, or dyspnoea were reported by $12.7 \%$ of exposed subjects $(n=19)$. Fisher's exact and $\chi^{2}$ tests (table 4) indicated that work related respiratory symptoms were associated with CAB RAST, duration of employment, and GCB skin test positivity. A larger percentage of workers from the GCB warehouse and of maintenance workers reported work related symptoms when compared with the control group but this did not reach statistical significance as two workers from the control group reported symptoms despite their supposed non-exposure to raw GCB dust. The association of work related symptoms with GCB RAST was of borderline significance $\left(\chi^{2}=3.34,1 \mathrm{df}, \mathrm{p}=0.067\right)$. When stepwise binary logistic regression was carried out using these variables, the only significant variables associated with work related respiratory symptoms were CAB RAST $(p=0.001)$ (fig 2) and duration of employment $(p=0.003)$ (table 5). Thus the association of work related respiratory symptoms with GCB exposure and atopy appear to be of secondary importance to $\mathrm{CAB}$ exposure and duration of employment. The relative risk of work related symptoms for subjects with positive CAB RAST was 4.44 (95\% confidence interval (95\% CI) 1.97-10.01).

\section{RAST}

In this study, CAB and GCB RAST were determined by reference to the range of results in the control group (extraction area). Values in excess of the mean $+2.5 \mathrm{SD}$ were designated positive (GCB > $1.06 \%$ binding, CAB $>1.29 \%$ ). Because the distribution of both sets of RAST results was not normal or log normal, linear regression could not be performed. McNemar testing showed strong agreement between GCB and CAB RAST ( $p<$ 0.001 ) (table 6). The associations of CAB and GCB RAST with other factors on $\chi^{2}$ testing were similar, but only CAB RAST was associated with work

Table 3 Prevalence of work related respiratory symptoms, bronchial hyperresponsiveness, atopy, skin test, and RAST positivity in coffee workers $(n=150)$

\begin{tabular}{lc}
\hline Symptom & No (\%) \\
\hline Work related respiratory symptoms & $19(12 \cdot 7)$ \\
Bronchial hyperresponsiveness & $45(30 \cdot 0)$ \\
Atopy & $81(54 \cdot 0)$ \\
Positive skin prick test to GCB & $22(14 \cdot 7)$ \\
Positive IgE RAST to GCB & $21(14 \cdot 0)$ \\
Positive IgE RAST to CAB & $22(14 \cdot 7)$ \\
Positive IgE RAST to fungal extracts $(\mathrm{n}=19)$ & $0(0)$ \\
\hline
\end{tabular}


Table 4 Associations of work related respiratory symptoms, CAB RAST, GCB RAST, GCB skin prick test positivity, and bronchial responsiveness

\begin{tabular}{|c|c|c|c|c|c|c|c|c|c|}
\hline \multirow[b]{2}{*}{ Variable } & \multicolumn{9}{|l|}{ Variable } \\
\hline & $\begin{array}{l}\text { Work related } \\
\text { respiratory } \\
\text { symptoms }\end{array}$ & $\begin{array}{l}C A B \\
R A S T\end{array}$ & $\begin{array}{l}G C B \\
R A S T\end{array}$ & $\begin{array}{l}\text { GCB skin } \\
\text { prick test }\end{array}$ & $\begin{array}{l}\text { Bronchial } \\
\text { hyperrespon- } \\
\text { siveness }\end{array}$ & Atopy & $\begin{array}{l}\text { Duration of } \\
\text { employment }\end{array}$ & $F E V_{1} \dagger$ & Smoking $\ddagger$ \\
\hline $\begin{array}{l}\text { Work related } \\
\text { respiratory symptoms }\end{array}$ & & $\begin{array}{l}\text { FET } \\
p=0.001\end{array}$ & & $\begin{array}{l}\text { FET } \\
p=0.002\end{array}$ & & NS & $\begin{array}{l}\chi^{2}=6.28 \\
p<0.05\end{array}$ & NS & NS \\
\hline CAB RAST & & & FET & $\begin{array}{l}\text { p=0 } \\
\text { FET }\end{array}$ & FET & $\chi^{2}=9.65$ & NS & NS & NS \\
\hline GCB RAST & & & & FET & FET & $\chi^{2}=7 \cdot 14$ & NS & NS & NS \\
\hline GCB skin prick test & & & & & $\begin{array}{l}\mathrm{FET} \\
\mathrm{p}=0.001\end{array}$ & $\begin{array}{l}\chi^{2}=8.66 \\
p<0.01\end{array}$ & NS & NS & $\begin{array}{l}\chi^{2}=6.94 \\
\mathrm{p}<0.01\end{array}$ \\
\hline $\begin{array}{l}\text { Bronchial } \\
\text { hyperresponsiveness }\end{array}$ & & & & & & $\begin{array}{l}\chi^{2}=7.52 \\
p<0.05\end{array}$ & $\begin{array}{l}\chi^{2}=5.66 \\
p<0.05\end{array}$ & $\begin{array}{l}\text { FET } \\
p=0.01\end{array}$ & NS \\
\hline Atopy & & & & & & & NS & NS & $\begin{array}{l}\chi^{2}=2.97 \\
\mathrm{p}<0.1\end{array}$ \\
\hline
\end{tabular}

Based on $2 \times 2$ contingency tables for positive and negative results.

*Arbitrary cut off point for short duration of employment = eight years (median duration of employment of the workforce).

tCut off point for low $\mathrm{FEV}_{1}=70 \%$ predicted value for age and height.

† Smoking includes current and ex-smokers.

FET $=$ Fisher's exact test.

related respiratory symptoms (table 4 ). The significant independent associations of CAB RAST positivity were GCB skin test $(p<0.001)$ and GCB RAST ( $p=0.006)$; and for GCB RAST, the significant independent associations were GCB skin test $(p<0.001)$ and CAB RAST $(p=0.006)$ (table 5). Subjects with work related respiratory symptoms were tested for specific IgE to fungal extracts; none were positive.

\section{CROSS REACTIVITY BETWEEN COFFEE AND CASTOR BEAN EXTRACTS}

RAST inhibition with CAB discs showed that at a 1:100 dilution of extracts, GCB extract did not inhibit, whereas the $\mathrm{CAB}$ extract gave $90 \%$ inhibition (fig 3A). With GCB discs, the GCB extract gave a dose dependent inhibition as expected, whereas the response to CAB extract showed an enhancement of binding at low concentrations, presumably due to non-specific binding to the disc and very limited inhibition at high concentrations (fig 3B).

\section{ATOPY}

The prevalence of atopy was $54 \cdot 0 \%$. Table 4 shows the significant associations. The factors independently associated with atopy were GCB RAST positivity $(p=0.005)$ and smoking $(p=0.005)$ (table 5).

Green coffee bean skin test positivity was significantly associated with work related respiratory symptoms, GCB and CAB RAST, bronchial hyperresponsiveness, atopy, and smoking (table 4) but CAB RAST positivity $(p<0.001)$ and GCB RAST $(p=$ 0.003 ) were the only significant independent associations (table 5).
BRONCHIAL HYPERRESPONSIVENESS

The prevalence of bronchial hyperresponsiveness was $30 \%$. It was not significantly associated with work related respiratory symptoms, but $\chi^{2}$ testing showed it to be associated with GCB and CAB RAST, GCB SPT, atopy, resting FEV , and duration of employment (table 4). The FEV F $_{1}(p=0.01)$, GCB RAST ( $p=0.004$ ), and duration of employment ( $p=0.002)$ were the only factors that were independently related to bronchial hyperresponsiveness (table 5).

\section{Discussion}

This study of $80 \%$ of the production workforce of a

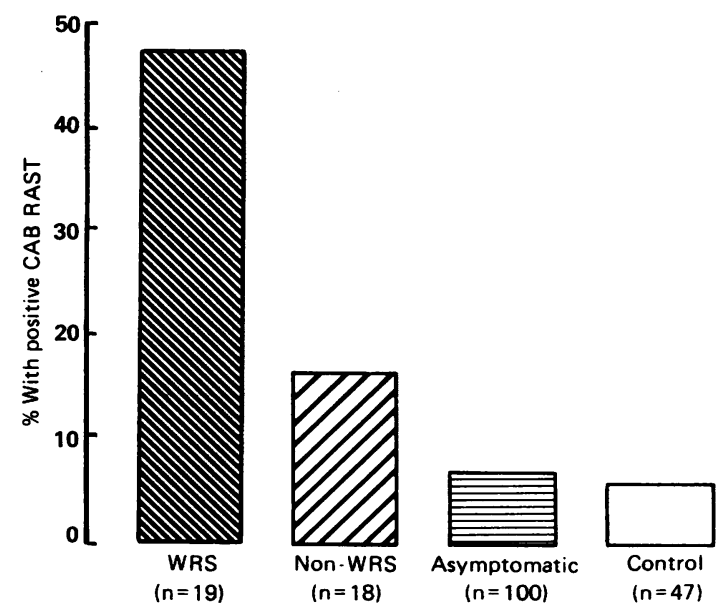

Figure 2 Relation between positive CAB RAST and work related respiratory symptoms (WRS). 
Table 5 Summary of stepwise binary logistic regression showing significant independent associations of each variable in order of importance

\begin{tabular}{|c|c|c|c|}
\hline Dependent variable & Factor & Improvement $\chi^{2}$ & p Value \\
\hline Work related respiratory symptoms & $\begin{array}{l}\text { CAB RAST } \\
\text { Duration of employment }\end{array}$ & $\begin{array}{r}11 \cdot 44 \\
8 \cdot 54\end{array}$ & $\begin{array}{l}0.001 \\
0.003\end{array}$ \\
\hline CAB RAST & $\begin{array}{l}\text { GCB skin prick test } \\
\text { GCB RAST } \\
\text { Work related respiratory symptoms }\end{array}$ & $\begin{array}{r}43 \cdot 11 \\
7 \cdot 51 \\
3 \cdot 56\end{array}$ & $\begin{array}{l}<0.001 \\
0.006 \\
0.059(\mathrm{NS})\end{array}$ \\
\hline GCB RAST & $\begin{array}{l}\text { GCB skin prick test } \\
\text { CAB RAST }\end{array}$ & $\begin{array}{r}43 \cdot 32 \\
7 \cdot 53\end{array}$ & $\begin{array}{r}<0.001 \\
0.006\end{array}$ \\
\hline GCB skin prick test & $\begin{array}{l}\text { CAB RAST } \\
\text { GCB RAST } \\
\text { Smoking }\end{array}$ & $\begin{array}{r}43.98 \\
8.68 \\
3 \cdot 12\end{array}$ & $\begin{array}{l}<0.001 \\
0.003 \\
0.077 \text { (NS) }\end{array}$ \\
\hline Bronchial hyperresponsiveness & $\begin{array}{l}\text { GCB RAST } \\
\text { Duration of employment } \\
\text { FEV }\end{array}$ & $\begin{array}{l}8 \cdot 39 \\
9 \cdot 33 \\
6 \cdot 64\end{array}$ & $\begin{array}{l}0.004 \\
0.002 \\
0.01\end{array}$ \\
\hline Atopy & $\begin{array}{l}\text { GCB RAST } \\
\text { Smoking }\end{array}$ & $\begin{array}{l}8 \cdot 03 \\
7 \cdot 87\end{array}$ & $\begin{array}{l}0.005 \\
0.005\end{array}$ \\
\hline
\end{tabular}

coffee processing factory has shown that the only significant factors contributing independently to work related respiratory symptoms were a positive CAB RAST and duration of employment. There was a strong correlation between GCB and CAB RAST as previously reported, ${ }^{5}$ but RAST inhibition studies showed that this was not a result of allergenic cross reactivity of the extracts. These results are supported by the finding that several sera were RAST positive to $\mathrm{CAB}$ but not $\mathrm{GCB}$ and vice versa. The allergens of GCB and CAB have been well characterised and have also been found to be distinct by other investigators. ${ }^{41920}$ Castor bean extract is a highly potent allergen and may promote sensitisation to GCB. This high potency may explain why sensitisation occurred with an equal frequency in non-atopic and atopic subjects in a CAB exposed population in Marseilles, France. ${ }^{21}$ Thorpe and coworkers ${ }^{21}$ have shown that this could be due to the ability of CAB to provoke a long lived IgE response by alteration of normal $\mathrm{T}$ cell function, perhaps explaining why CAB sensitisation appears to override the effects of atopy, bronchial hyperresponsiveness, smoking, and GCB sensitisation in the development of work related respiratory symptoms. The prevalence of bronchial hyperresponsiveness in this group was slightly greater than

Table 6 Association of CAB RAST and GCB RAST: numbers of subjects with positive tests

\begin{tabular}{lll}
\hline & \multicolumn{2}{l}{$G C B$ RAST } \\
\cline { 2 - 3 } & Positive & Negative \\
\hline CAB RAST: & 15 & 7 \\
$\begin{array}{l}\text { Positive } \\
\text { Negative }\end{array}$ & 6 & 116 \\
\hline
\end{tabular}

Relative risk ratio for presence of GCB RAST positivity in the presence of CAB RAST positivity $=15 / 22$ divided by $6 / 122=$ $13.88(95 \%$ CI 6.03-31.91). that in a normal general practice population $(23 \cdot 2 \%)$ studied using the same tests and criteria. ${ }^{22}$ The variables significantly and independently associated with bronchial hyperresponsiveness were different, however, from those in the general population. The association with GCB exposure was predominant, overriding the effects of atopy and smoking but not resting $\mathrm{FEV}_{1}$. Although bronchial hyperresponsiveness was not an independently significant association of work related respiratory symptoms, GCB exposure might be contributing to the development of bronchial hyperresponsiveness independently of the effect of $\mathrm{CAB}$ positivity. It is possible that the association of GCB sensitisation with bronchial hyperresponsiveness and work related respiratory symptoms might predominate were it not for the influence of the potent $\mathrm{CAB}$ allergen. It would currently be difficult, however, to locate a group of GCB exposed subjects who had not been exposed to CAB in whom the independent effects of GCB exposure on work related respiratory symptoms and bronchial hyperresponsiveness could be studied.

The prevalence of atopy $(54 \%)$ was higher than expected in a general practice population but it did not appear to be a predisposing factor for either GCB or $\mathrm{CAB}$ sensitisation, again reflecting the overriding effect of the CAB antigen. Smoking was independently associated with atopy as has been shown previously, ${ }^{2324}$ and was also of borderline significance $(p=0.08)$ as a factor independently associated with GCB skin test positivity; it may, therefore, be contributing to GCB sensitisation. Zetterstrom et al have previously shown that smokers are more at risk of occupational allergy. ${ }^{25}$ Aerobiological surveys showed that fungal contaminants from the coffee dust contributed to the workplace air so that certain species such as the aspergilli were present in greater concentrations than may be expected out of doors or in an uncontaminated indoor environment. They 


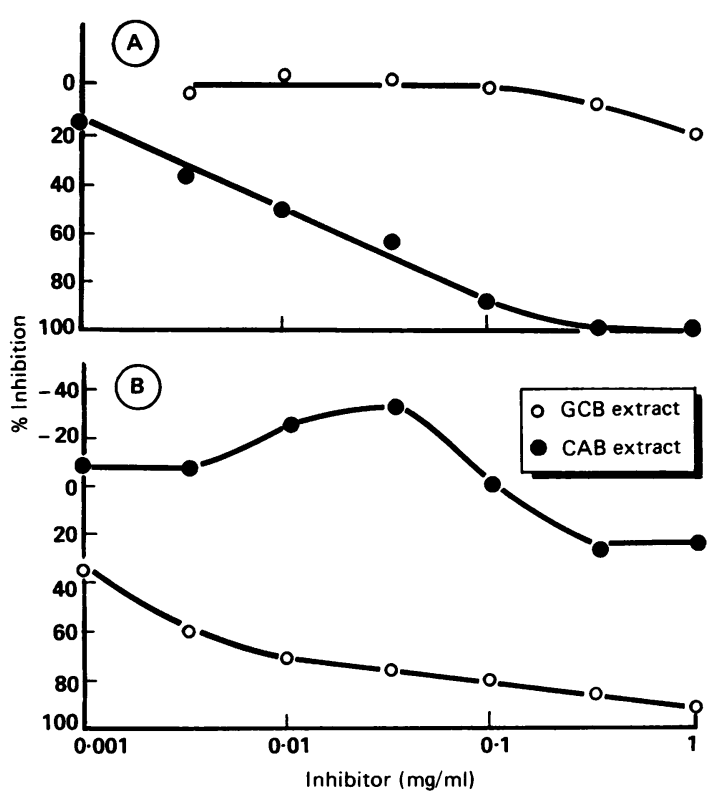

Figure 3 RAST inhibition of $C A B$ and $G C B$ specific IgE by $G C B$ extract and $C A B$ extract: $(A) C A B$ extract discs; $(B)$ $G C B$ extract discs.

were fewer in number, however, compared with agricultural activities more often associated with work related symptoms. ${ }^{26}$ This is supported by the finding that none of the subjects with work related respiratory symptoms had specific IgE to fungal extracts. Entomological analysis of dust indicated that workers were not occupationally exposed to storage mites.

Castor bean has been known since 1950 to be a highly potent allergen and a potential contaminant of raw GCB $^{1}$ and the awareness of this has led to a widespread change in the working practise in this factory. Handling of sacks between the container lorry and the tipping area is now completely automated and extraction facilities within the containers themselves have also been improved. Since 1985 the exposed workforce has been decreased by two thirds through automation. Also raw GCBs are now transported in burlap sacks that have not been used for any other product to eliminate the risk of contamination. It is still possible that some sacks may have been previously used for other products, although analysis of a sample of five burlap sacks showed no CAB antigen. A factory dust sample was also negative for $C A B$ antigen suggesting that $C A B$ contamination has been eliminated from the factory or has been decreased to below the threshold of detection. Because of the potency of the $C A B$ such low exposures may still cause sensitisation and explain why several workers only recently employed had a positive CAB RAST.

The significant association of duration of employment with respiratory symptoms might imply that past exposure to $\mathrm{CAB}$ is important, particularly as most affected workers had been employed for more than eight years. Workers with the worst symptoms may leave the industry early in their employment, however, because they cannot tolerate the working environment (the survivor principle). In this situation, symptomatic workers among the newly employed population might be replaced at a more rapid rate than those employed for longer, who have been able to tolerate their work related respiratory symptoms. Since this study was completed no new cases of work related respiratory symptoms have been reported to the factory doctor. Those identified as having work related symptoms have either moved to different areas where they are no longer exposed to raw GCBs or they have retired. Although perhaps no longer a problem in the processing plant studied, contamination of raw GCBs by CAB is potentially still a problem in the coffee industry. All practices to minimise the exposure of the workforce to this antigen should continue.

B Crook was supported during this work by a Health and Safety Executive contract No 1/MS/216/209/85.

1 Figley KD, Rawling FA. Castor bean: an industrial hazard as a contaminant of green coffee dust and used burlap bags. Journal of Allergy 1950;21:545-58.

2 Zuskin E, Valic F, Skuric $Z$. Respiratory function in coffee workers. Br J Ind Med 1979;36:117-22.

3 Karr RM, Lehrer SB, Butcher BT, Salvaggio JE. Coffee worker's asthma: a clinical appraisal using the radioallergosorbent test. J Allergy Clin Immunol 1978;62:143-8.

4 Osterman K, Zetterstrom O, Johansson SGO. Coffee worker's allergy. Allergy 1982;37:313-22.

5 Osterman K, Johansson SGO, Zetterstrom O. Diagnostic tests in allergy to green coffee. Allergy 1985;40:336-43.

6 Cockcroft DW, Ruffin RE, Dolovich J, Hargreave FE. Allergeninduced increase in non-allergenic bronchial reactivity. Clin Allergy 1977;7:503-13.

7 Cockcroft DW, Cotton DJ, Mink JT. Non-specific bronchial hyperreactivity after exposure to Western Red Cedar. Am Rev Respir Dis 1979;119:505.

8 Juniper EF, Frith PA, Hargreave FE. Airways responsiveness to histamine and methacholine. Relationship to minimum treatment to control symptoms of asthma. Thorax 1981;36:575-9.

9 Medical Research Council, Committee on the Aetiology of Chronic Bronchitis. Standardised questionnaire on respiratory symptoms. Br Med J 1960;2:1665.

10 Bennett J, Osman J, Blainey AD, Davies RJ. The assessment of a computer administered questionnaire in the differential diagnosis of asthma and chronic airflow obstruction. BrJDis Chest 1988;82:268-73.

11 Blainey AD, Topping MD, Ollier S, Davies RJ. Respiratory symptoms in arable farmworkers: role of storage mites. Thorax 1988;43:697-702.

12 Bennett JB, Davies RJ. A comparison of histamine and methacholine bronchial challenges using the DeVilbiss 646 nebuliser and the Rosenthal-French dosimeter. Br J Dis Chest 1987; 81:252-9.

13 Health and Safety Executive. Methods for the determination of hazardous substances No 14. General methods for the gravimetric determination of respirable and total inhalable dust. London: HMSO, 1986. 
14 Andersen AA. New sampler for the collection, sizing and enumeration of viable airborne particles. $J$ Bacteriol 1958 ; 76:471-84.

15 King AD, Hocking AD, Pitt JI. Dichloran-rose bengal medium for enumeration and isolation of moulds from foods. Appl Environ Microbiol 1979;37:959-64.

16 Hocking AD, Pitt JI. Dichloran-glycerol medium for enumeration of xerophilic fungi from low-moisture foods. Appl Environ Microbiol 1980;39:488-92.

17 Armitage P. Statistical Methods in Medical Research. London: Blackwell Scientific Publications, 1971:135-8.

18 Armitage P. Statistical Methods in Medical Research. London: Blackwell Scientific Publications, 1971:127.

19 Lehrer SB, Karr RM, Salvaggio JE. Extraction and analysis of coffee bean allergens. Clin Allergy 1978;8:217-26.

20 Coulson EJ, Spies JR, Stevens H. Identification of castor bean allergen in green coffee. Journal of Allergy 1950;21:554-8.

21 Thorpe SC, Kemeny DM, Panzani R, Lessof MH. Allergy to castor bean. 1. Its relationship to sensitisation to common inhalant allergens (atopy). J Allergy Clin Immunol 1988;82: 62-6.
22 Trigg CJ, Bennett JB, Tooley M, Sibbald B, D'Souza MR, Davies RJ. A general practice based survey of bronchial hyperresponsiveness and its relation to symptoms, sex, age, atopy and smoking. Thorax 1990;45:866-72.

23 Taylor RG, Gross E, Joyce H, Holland F, Pride NB. Smoking, allergy and the differential white cell blood count. Thorax 1985;40:17-22.

24 Gerrard JW, Heiner DC, Ko CG, Mink J, Meyers A, Dosman JA. Immunoglobulin levels in smokers and non-smokers. $A n n$ Allergy 1980;44:261-2.

25 Zetterstrom O, Osterman K, Machado L, Johansson SGO Another smoking hazard: raised serum IgE concentration and increased risk of occupational allergy. $\mathrm{Br} M e d \mathrm{~J} 1981$; 283:1215-7.

26 Crook B, Lacey J. Enumeration of airborne micro-organisms in work environments. Environmental Technology Letters 1988; 9:515-20.

Accepted 12 November 1990

\section{Correspondence and editorials}

The British Journal of Industrial Medicine welcomes correspondence relating to any of the material appearing in the journal. Results from preliminary or small scale studies may also be published in the correspondence column if this seems appropriate. Letters should be not more than $\mathbf{5 0 0}$ words in length and contain a minimum of references. Table and figures should be kept to an absolute minimum. Letters are accepted on the understanding that they may be subject to editorial revision and shortening.

The journal now also publishes editorials which are normally specially commissioned. The Editor welcomes suggestions regarding suitable topics; those wishing to submit an editorial, however, should do so only after discussion with the Editor. 